\title{
The Web as a learning environment
}

\author{
Focus on contents vs. focus on the search process
}

\author{
Francesco Caviglia ${ }^{1,2}$ and Maria Ferraris ${ }^{1}$ \\ ${ }^{1}$ CNR- Institute for Educational Technology, Via De Marini 6, 16149 \\ Genova, Italy \\ 2 Ph.D. student at Doctoral School in Education and Learning Sciences, \\ Ca' Foscari University, Venezia, Italy \\ \{caviglia,ferraris\}@itd.cnr.it, \\ WWW home page: http://www.itd.cnr.it
}

\begin{abstract}
The Web is typically used, in educational settings, as a repository of contents to be learned. Within this approach, the Web-searching process tends to be perceived merely as an obstacle on the way to the contents. This paper suggests instead that searching the Web requires information problem solving competences which are in themselves key requisites for literacy in a knowledge society and deserve to be fostered as explicit goals in educational settings. Given the complexity of the competences involved, it is suggested that educational intervention focus on practice with information problems which should be thin in content, but rich in opportunities for bringing to the foreground some critical areas of the information problem solving process.
\end{abstract}

\section{Introduction}

If one takes into account the most widespread metaphors of the Web [1], at least of the Web 1.0 which is the focus of this paper, two main patterns emerge. The first corresponds to a focus on the information contained in the Web, and considers the Web as a container, a virtual library, an encyclopedia. It is a static and tangible view, which gives value to the places one can arrive at, and to the quality of the information they deliver. A second cluster of metaphors corresponds instead to a more dynamic and abstract view of the Web as a space for traveling. In this case, not just the destination places are valued, but rather the paths one walks to reach them, and the quality of the journey.

In considering how the Web can be used in educational settings, the container or library metaphor corresponds to a focus on the contents the learner is required to access. From this point of view, learning how to move through information to reach a goal is indeed important, but only as a prerequisite for accessing valuable contents. Therefore, teachers often choose to provide the learner with a list of pre-selected 
websites, to spare time or to prevent bad encounters on the Web. Such a protective attitude, however, fails to promote the learner's ability to find her/his way around and to develop her/his own maps and connections. To foster autonomy, it is necessary instead to shift focus from the contents to the processes activated by the learner in conjunction with the task of solving an information problem on the Web; that is, to shift from the web-as-container to the web-as-space-for-traveling metaphor.

Research on Web searching suggests that information problem solving on the Web is a complex, highly dynamic process, under the influence of factors such as the user's familiarity with the Web, her/his cognitive style, motivation, perseverance, as well as her/his prior knowledge on the topic and the type of problem [2,3 and others that can not be mentioned due to space constraints]. Knowing the way search engines operate and the way information is organized on the Web seem no warrant that a user will be successful in solving information problems: several experiences of educational intervention ([4], Kuiper, Volman and Terwel in [5], Walraven, BrandGruwel and Boshuizen in [5]) suggest indeed that learning the technicalities of the Web should go hand in hand with the development of the broader competences, strategies and attitudes that lay at the basis of a knowledgeable use of information resources, such as being able to identify one's information needs and translate them in questions, to understand a text, to assess the trustworthiness and relevance of a piece of information, to adapt one's strategy to the results of the search process.

This paper, based on research and teacher education activities carried out since 2002 and in part accounted for in [6,7], suggests that those competences can be fostered by means of frequent, unassuming practices on the web, based on information problems designed to highlight crucial issues of the search process.

\section{Highlights on the process}

Let us imagine to engage a group of students with questions out of pure curiosity: "Was Einstein indeed a bad student?"; "What is the name of the Botswana currency and why is it called so?"; "You are traveling to Easter Island in February. Will you take your swimsuit with you?"; "Why does Genoa Football team wear red and blue?". These questions are not especially relevant in themselves and do not require any specialized content knowledge, nor advanced Web proficiency. However, they are nontrivial as long as no ready-made solutions are available (which was true at the time of our experiences) or the existing answers contradict each other.

The students and teachers with whom we tried these and other questions differed widely in their search strategies. Some of them tried to locate a pre-defined "correct answer", while others showed a more flexible attitude and tried to figure out by themselves some possible answers, maybe based on wrong assumptions such as "It is cold in February, I should not need my swimsuit". Some of them got rid of the problem ("I looked in the Genoa website and it does not say anything. There is nothing on this on the Web"), others drew hasty conclusions from the information they encountered ("This site shows Einstein's school report, it's full of 4 and 5, he was indeed a bad student"). But when the teacher managed to promote doubts and 
further questioning - for example, by suggesting, in the case of Einstein's reports, that mark systems differ across countries - the enacted process made it possible to highlight some unfortunate attitudes and to exercise some competences that are critical for the use of information resources. In the following, we will focus on three of such competences.

Asking questions The most distinctive feature of the Web, compared with paperbased material, is that the user has to ask questions to gain access to information. In a way, the Web restores the natural order of things: asking comes before answering. We use the verb "to restore" because learning at school is typically a matter of acquiring answers. On the Web, asking questions is easy, almost unavoidable, and does not put one's face at risk, while incremental refinement of the search string is always possible. In the whole, the Web is an excellent environment for cultivating doubt and curiosity, that is for initiating the learning process by recognizing one's lack of information and one's interest in broadening one's understanding.

Building hypotheses While navigating on the Web, at any moment the user is faced with choices: "Shall I start reading this or that?"; "Shall I rephrase my search?"; "Is this piece of information reliable"? Many of these decisions will be taken on the basis of abductive inferences. For example, choosing a link to follow from a list of results of a query implies making a prediction about the content of a web pages, on the basis of cues from the page description. Abduction is also behind the construction of possible answers to the information problem. For example, when some of our students discovered that Genoa Football Club had been founded by Englishmen, they wondered whether there was a link between this British background and the team colors, and looked on the Web to confirm this (correct) hypothesis. The Web, as a place where abduction is ubiquitous in the process of information problem solving, can thus become a place for raising awareness of a crucial cognitive tool which has long been neglected in scholarly tradition [8] and hence in educational practice.

Recognizing trustworthiness Information problem solving on the Web does not only require asking questions and building hypotheses, but also understanding answers, assessing them for relevance and trustworthiness, recognizing contradictions. For example, Web searches about Einstein as a student return a majority of pages stating that he was indeed a bad student, but also pages stating the contrary. To settle the controversy, the user needs to further look for more pieces of evidence and to decide which sources are the most reliable. The high rate of information pollution on the Web thus highlights the need for 'critical literacy' skills. However, these skills are also crucial outside the Web. Therefore, the variable quality of information on the web can be regarded as an opportunity for real-life practice in critical literacy and for conveying the message that not everything is on the Web, and that Web-based information is not always the best information. In other words, that the Web is a good place for asking questions, but not necessarily the best place for finding answers. 


\section{Conclusions}

As any new technology, the Web is being used after the model of pre-existing ones. It is therefore not surprising that the Web has become, in educational settings, an alternative to books as a source of information for schoolwork, with some negative effects, such as plagiarism, shallowness, disregard for other sources. However, these effects should not be ascribed as much to the Web itself, but rather to the kind of tasks the students are required to perform, as far as those tasks focus on reproduction or, in best case, integration of contents; such tasks reveal a view of learning as expanding the quantity of the contents the student is asked to acquire. But, paradoxically, it is the Web itself, with its ever-growing number of pages, to reveal how such a view is unrealistic face to the huge and fast-changing body of knowledge in today's society. What has become important, inside and outside the Web, is being able to move through information in a knowledgeable way, to ask questions, to assess answers, to deepen one's understanding. These competences seem indeed to be lacking even among young people who are highly familiar with technology [9]. A focus on the process of Web searching and navigating - as suggested throughout this paper - emerges therefore as a fruitful area for educational intervention.

\section{References}

1. L. Ratzan, Making sense of the Web: a metaphorical approach, Information Research, 6(1) (2000); http://informationr.net/ir/6-1/paper85.html.

2. C. Hölscher and G. Strube, Web search behavior of Internet experts and newbies, Computer Networks, 33, 337-346 (2000).

3. D. Bilal and J. Kirby, Differences and similarities in information seeking: children and adults as Web users, Information Processing and Management, 38, 649670 ( 2002).

4. E. Kuiper, M. Volman, and J. Terwel, The Web as an Information Resource in K-12 Education: Strategies for Supporting Students in Searching and Processing Information, Review of Educational Research, 75(3), 285-328 (2005).

5. S. Brand-Gruwel and P. Gerjets (Eds), Instructional Support for Enhancing Students' Information Problem Solving Ability. Computers in Human Behavior, 24(3), 615-1914 (May 2008).

6. M. Ferraris, Navigare sul WWW a scuola. Ma per andare dove? [Navigating on the WWW at school. To go where?], TD-Tecnologie Didattiche, 28, 29-41 (2003).

7. F. Caviglia and M. Ferraris, Web-searching for learning: observing proficient web users working out an information problem, Proc. IADIS Conference on Cognition and Exploratory Learning in Digital Age, 440-442, (2006).

8. L. Magnani, N.J. Nersessian, and P. Thagard, Preface to "Model-based reasoning in science: learning and discovery," Foundations of Science, 5(2), 121-127 (2000).

9. J. Nielsen, Usability of Websites for Teenagers (January 2005); http://www.useit.com/alertbox/teenagers.html. 